\title{
A Novel Ambipolar Spirobifluorene Derivative that Behaves as an Efficient Blue-Light Emitter in Organic Light-Emitting Diodes
}

2007

Vol. 9, No. 22

$4511-4514$

\author{
Yuan-Li Liao, ${ }^{\dagger}$ Chi-Yen Lin, ${ }^{\dagger}$ Ken-Tsung Wong, ${ }^{*}, \dagger$ Tei-Hung Hou, ${ }^{\ddagger}$ and \\ Wen-Yi Hung ${ }^{\star, \neq}$
}

Department of Chemistry, National Taiwan University, Taipei 106, Taiwan, and Institute of Optoelectronic Sciences, National Taiwan Ocean University, Keelung, Taiwan 202

kenwong@ntu.edu.tw; wenhung@mail.ntou.edu.tw

Received August 15, 2007

\section{ABSTRACT}

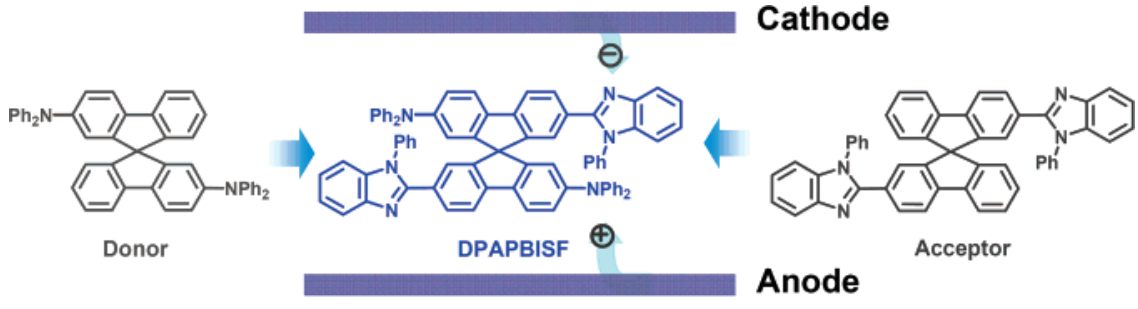

A novel ambipolar spiro-configured D-A blue-light emitter bearing hole-transporting diphenylamino groups and electron-transporting phenylbenzimidazole groups was synthesized, characterized, and incorporated into an efficient single-layer organic light-emitting diode (OLED) device exhibiting blue-emission Commission International d'Eclairage (CIE) coordinates of 0.15 and 0.14 , a turn-on potential of $4 \mathrm{~V}$, a maximum brightness of $2800 \mathrm{~cd} / \mathrm{m}^{2}$ at $830 \mathrm{~mA} / \mathrm{cm}^{2}(19 \mathrm{~V})$, and a maximum quantum efficiency of $0.53 \%(0.61 \mathrm{~cd} / \mathrm{A})$.

9,9'-Spirobifluorene-cored compounds have been employed widely in organic light-emitting diodes (OLEDs) displaying a variety of functions. ${ }^{1}$ A common strategy toward manipulating the electronic structure, emission spectrum, thermal/ morphological stability, or charge carrier mobility of 9,9' spirobifluorene-based materials is through tailoring the nature of the substituents and their substitution patterns about the 9,9'-spirobifluorene unit, e.g., with identical or different substituents positioned on the same or different biphenyl branch. ${ }^{2}$ Furthermore, to balance the electron-hole recombination efficiency, one promising strategy is that of devel-

\footnotetext{
$\dagger$ National Taiwan University.
}

$\doteqdot$ National Taiwan Ocean University.

(1) Saragi, T. P. I.; Spehr, T.; Siebert, A.; Fuhrmann-Lieker, T.; Salbeck, J. Chem. Rev. 2007, 107, 1011.

(2) (a) Pudzich, R.; Salbeck, J. Synth. Met. 2003, 138, 21. (b) Lin, H.W.; Ku, S.-Y.; Su, H.-C.; Huang, C.-W.; Lin, Y.-T.; Wong, K.-T.; Wu, C.-C. Adv. Mater. 2005, 17, 2489. oping emitters equipped with an electron-donating moiety (D) that facilitates hole injection and/or transport and an electron-withdrawing moiety (A) that improves electron injection and/or transport. ${ }^{3}$ With appropriate choices of the $\mathrm{D}$ and $\mathrm{A}$ units, the levels of the highest occupied molecular orbital (HOMO) and lowest unoccupied molecular orbital (LUMO) as well as the emission color of the $\mathrm{D}-\mathrm{A}$ molecule can be controlled to a fine degree, ${ }^{4}$ making such systems increasingly attractive for use in a single-layer OLEDs. ${ }^{5}$ This approach has allowed the development of efficient emitters displaying a range of emission colors. ${ }^{1,6}$ However, derivatives

(3) Shirota, Y.; Kinoshita, M.; Noda, T.; Okumoto, K.; Ohara, T. J. Am. Chem. Soc. 2000, 122, 11021.

(4) (a) Zhu, Y.; Kulkarni, A. P.; Jenekhe, S. A. Chem. Mater. 2005, 17, 5225. (b) Chen, C.-T.; Lin, J.-S.; Moturu, M. V. R. K.; Lin, Y.-W.; Yi, W.; Tao, Y.-T.; Chen, C.-H. Chem. Commun. 2005, 16, 3980. (c) Xu, X.; Chen, S.; Yu, G.; Di, C.; You, H.; Ma, D.; Liu, Y. Adv. Mater. 2007, 19, 1281. (d) Haung, T.-H.; Lin, J.-T.; Chen, L.-Y.; Lin, Y.-T.; Wu, C.-C. Adv. Mater. 2006, 18, 602 . 
featuring donors on one biphenyl branch spiro-linked to another biphenyl moiety bearing acceptors exhibit low photoluminescence efficiencies as a result of strong photoinduced electron transfer. ${ }^{7}$ Thus, a better alternative is to position the $\mathrm{D}$ and $\mathrm{A}$ moieties on the same biphenyl branch of the spirobifluorene. Unfortunately, strong intramolecular D-A charge transfer normally leads to significant redshifting of the emission colors, making it difficult to develop efficient blue emitters using this strategy. ${ }^{1,2,6}$

Herein, we report an efficient spiro-configured D-A bipolar blue emitter, 2,2'-bis(diphenylamino)-7,7'-bis(diphenylbenzimidazole)-9, $9^{\prime}$-spirobifluorene $(\mathbf{3}$, Scheme 1$)$. The

Scheme 1. Synthetic Route toward Molecule $\mathbf{3}$ and Structures of the Single Functional Counterparts $\mathbf{4}$ and $\mathbf{5}$
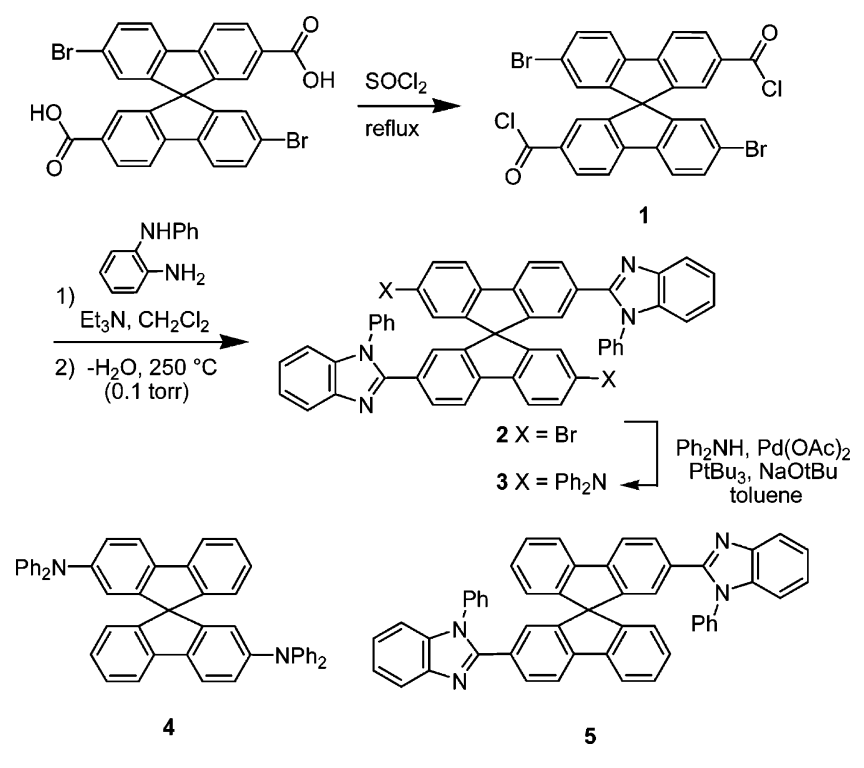

phenylbenzimidazole units were introduced as electronaccepting (A) substituents because 1,3,5-tris( $N$-phenylbenzimidizol-2-yl)benzene (TPBI), which exhibits good electron transport mobility, ${ }^{8}$ has been used widely as an electron transport material for OLEDs. The diphenylamino groups were introduced as electron-donating (D) groups because the corresponding donor-only analogue $2,2^{\prime}$-bis(diphenylamino)$9,9^{\prime}$-spirobifluorene (4) has been used successfully as a holetransporting material in a highly efficient blue electrophosphorescent device. ${ }^{9}$ The two D-A chromophores are bonded perpendicularly through a tetrahedral carbon atom, leading

(5) (a) Li, Z. H.; Wong, M. S.; Fukutani, H.; Tao, Y. Org. Lett. 2006, 8 , 4271. (b) Habrard, F.; Ouisse, T.; Stephan, O.; Aubouy, L.; Gerbier, P.; Hirsch, L.; Huby, N.; Van der Lee, A. Synth. Met. 2006, 156, 1262. (c) Lee, T. H.; Tong, K. L.; So, S. K.; Leung, L. M. Synth. Met. 2005, 155 , 116.

(6) Chiang, C.-L.; Shu, C.-F.; Chen, C.-T. Org. Lett. 2005, 7, 3717.

(7) (a) Chien, Y.-Y.; Wong, K.-T.; Chou, P.-T.; Cheng, Y.-M. Chem. Commun. 2002, 2874. (b) Ku, S.-Y.; Cheng, Y.-M.; Lin, X.-Y.; Hung, Y.Y.; Pu, S.-C.; Wong, K.-T.; Chou, P.-T.; Lee, G.-H. J. Org. Chem. 2006, $71,456$.

(8) Hung, W.-Y.; Ke, T.-H.; Lin, Y.-T.; Wu, C.-C.; Hung, T.-H.; Chao, T.-C.; Wong, K.-T.; Wu, C.-I. Appl. Phys. Lett. 2006, 88, 164102.

(9) Tsai, M.-H.; Lin, H.-W.; Su, H.-C.; Ke, T.-H.; Wu, C.-C.; Fang, F.C.; Liao, Y.-L.; Wong, K.-T.; Wu, C.-I. Adv. Mater. 2006, 18, 1216. to an orthogonal configuration that impedes the $\pi$-orbital interactions between the individual $\mathrm{D}-\mathrm{A}$ chromophore branches. Moreover, the D and A moieties implanted onto a rigid and coplanar fluorene ring result in a blue-emissive molecule exhibiting bipolar character and high thermal stability, forming a multifunctional material having promising potential for application in OLEDs.

Scheme 1 depicts the synthesis of $\mathbf{3}$. Treatment of 2,2'dibromo-7, $7^{\prime}$-dicarboxyl-9, $9^{\prime}$-spirobifluorene ${ }^{2}$ with an excess of $\mathrm{SOCl}_{2}$ gave the diacyl chloride intermediate $\mathbf{1}$, which was amidated with $N$-phenyl-o-phenylenediamine in the presence of triethylamine followed by dehydration at $250{ }^{\circ} \mathrm{C}$ under vacuum ( 0.1 Torr) to afford the dibromide 2 (60\% for three steps). The diphenylamino groups were introduced through amination of 2 with diphenylamine and $\mathrm{NaO}^{t} \mathrm{Bu}$ in the presence of catalytic amounts of $\mathrm{Pd}(\mathrm{OAc})_{2}$ and $\mathrm{P}^{t} \mathrm{Bu}_{3}$, providing 3 in $83 \%$ yield. We synthesized the acceptor-only analogue, 2,2'-bis(phenylbenzimidazole)-9,9'-spirobifluorene (5), through a similar path (Scheme S-1, Supporting Information) for the sake of comparison and as an electrontransporting material in subsequent OLED devices.

Table 1 summarizes the physical properties of compounds 3-5. Differential scanning calorimetry (DSC) indicated that these compounds exhibit distinct glass transition temperatures $\left(T_{\mathrm{g}}\right)$ within the range from 115 to $165{ }^{\circ} \mathrm{C}$, suggesting that these materials could form homogeneous and amorphous films through thermal evaporation. Thermogravimetric analysis (TGA) indicated that these materials exhibit high decomposition temperatures $\left(T_{\mathrm{d}}\right)$ within the range from 370 to $477{ }^{\circ} \mathrm{C}$ (5\% weight loss). We attribute these relatively high morphological and thermal stabilities to the perpendicular configuration of the spirobifluorene core, which disrupts intermolecular interactions and suppresses the tendency to crystallize.

We first examined the bipolar character of $\mathbf{3}$ using cyclic voltammetry (CV; Figure S-1 in Supporting Information). The electrochemical properties of spirobifluorene derivatives are dependent mainly on their functional substituents. Thus, compound $\mathbf{4}$ exhibited only reversible oxidation potentials [0.87 and $0.94 \mathrm{~V}$, assigned by differential pulse voltammetry (DPV)], whereas the acceptor-only counterpart 5 displayed reversible reduction potentials $(-1.96$ and $-2.17 \mathrm{~V})$. Merging these two functionalities, the spiro-configured bipolar D-A molecule 3 exhibited both reversible oxidation and reduction behavior but with slight shifts in the potentials. The existence of stable radical cationic and anionic species for 3 suggested that it had great potential for efficient electron/hole transport and recombination in OLEDs. We estimated the HOMO energy levels from the oxidation potentials of $\mathbf{3}$ and $\mathbf{4}$ in relation to the first reversible oxidation potential $\left(0.74 \mathrm{~V}\right.$ in $\left.\mathrm{CH}_{2} \mathrm{Cl}_{2}\right)$ of $N, N^{\prime}$-bis-(1naphthyl)- $N, N^{\prime}$-diphenyl-1,1'-biphenyl-4,4'-diamine ( $\alpha$-NPB, $\mathrm{HOMO}=-5.3 \mathrm{eV}) .{ }^{10} \mathrm{~A}$ band gap energy of $2.86 \mathrm{eV}$ for 3 was calculated from the difference between the reduction and oxidation peak potentials; this value is consistent with the data calculated from the optical absorption threshold. We

(10) D'Andrade, B. W.; Datta, S.; Forrest, S. R.; Djurovich, P.; Polikarpov, E.; Thompson, M. E. Org. Electron. 2005, 6, 11. 
Table 1. Physical Properties of Spirobifluorene Derivatives 3-5

\begin{tabular}{|c|c|c|c|c|c|c|c|c|c|}
\hline compd & $\begin{array}{c}T_{\mathrm{g}} \\
\left({ }^{\circ} \mathrm{C}\right)\end{array}$ & $\begin{array}{c}T_{\mathrm{d}} \\
\left({ }^{\circ} \mathrm{C}\right)\end{array}$ & $\begin{array}{c}E_{1 / 2} \mathrm{OX} \\
(\mathrm{V})^{\mathrm{a}}\end{array}$ & $\begin{array}{c}E_{1 / 2}{ }^{\mathrm{REV}} \\
(\mathrm{V})^{a}\end{array}$ & $\begin{array}{c}\mathrm{HOMO} \\
(\mathrm{eV})^{b}\end{array}$ & $\begin{array}{c}\text { LUMO } \\
(\mathrm{eV})\end{array}$ & $\begin{array}{l}\Delta E_{\mathrm{g}} \\
(\mathrm{eV})\end{array}$ & $\begin{array}{l}\operatorname{Abs} \lambda_{\max }(\mathrm{nm}) \\
\text { solution/film }\end{array}$ & $\begin{array}{l}\mathrm{PL} \lambda_{\max }(\mathrm{nm}) \\
\text { solution/film }\end{array}$ \\
\hline $\mathbf{3}$ & 165 & 477 & $0.90,0.97$ & $-1.96,-2.17$ & -5.46 & -2.60 & 2.86 & $307,386 / 310,381$ & $445 / 460$ \\
\hline 4 & 115 & 370 & $0.87,0.94$ & - & -5.43 & -2.26 & 3.17 & $352 / 356$ & $394 / 407$ \\
\hline 5 & 154 & 393 & - & -2.13 & -5.73 & -2.43 & 3.30 & $331 / 331$ & $383 / 392$ \\
\hline
\end{tabular}

deduced the corresponding LUMO energy level of $\mathbf{5}$ from the difference between the reduction potentials of $\mathbf{3}$ and $\mathbf{5}$. Table 1 summarizes the results.

Figure 1 displays the absorption and emission spectra of $\mathbf{3}-\mathbf{5}$ in solid films.

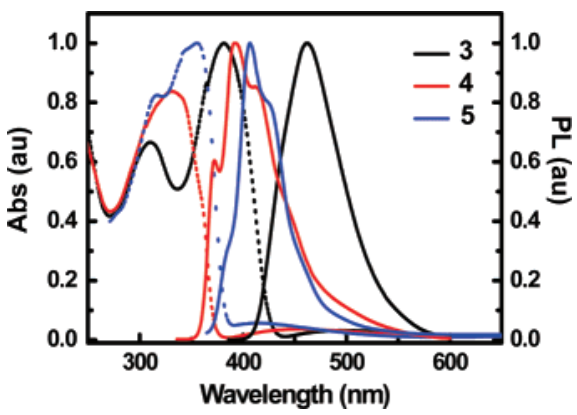

Figure 1. UV-vis absorption spectra (dotted lines) and photoluminescence spectra (solid lines) of $\mathbf{3 - 5}$ in solid films.

The absorption and emission maxima of $\mathbf{3}$ are significantly red-shifted relative to those of their single-chromophore counterparts, indicating that the $\pi$ conjugation was effectively extended once the D and A groups were connected into the $\mathrm{D}-\mathrm{A}$ chromophore. This result agrees with the observed lower band gap energy of $\mathbf{3}$ from the CV experiment. From a close inspection of the dependence of the absorption and emission behavior on solvent polarity (Figure S-2, Supporting Information), we found that the absorption maximum is relatively insensitive to the dielectric environment, whereas the emission characteristics of $\mathbf{3}$ revealed a strong solvatochromic effect. For example, the emission spectrum of $\mathbf{3}$ in cyclohexane exhibits a maximum signal at $412 \mathrm{~nm}$ that was red-shifted significantly to $468 \mathrm{~nm}$ in $\mathrm{MeCN}$. Because 3 exhibits absorption behavior that is independent of the solvent polarity, we infer that its reduced band gap energy results from $\pi$-orbital interactions between the $\mathrm{D}$ and $\mathrm{A}$ groups, without evident electronic interactions, in the ground state. The dependence of the emission wavelength of $\mathbf{3}$ on the solvent polarity is indicative of photoinduced charge transfer occurring in the excited state. Importantly, the photoluminescence quantum yields of $\mathbf{3}$ measured in thin film and in $\mathrm{CH}_{2} \mathrm{Cl}_{2}$ using an integrated sphere system are 0.41 and 0.84 , respectively, ensuring the potential use as an efficient emitter.

We conducted charge-carrier mobility measurements of 3-5 using time-of-flight (TOF) techniques at ambient temperature (Figure S-3, Supporting Information). ${ }^{11}$ Figure 2 depicts the mobilities plotted as a function of the square

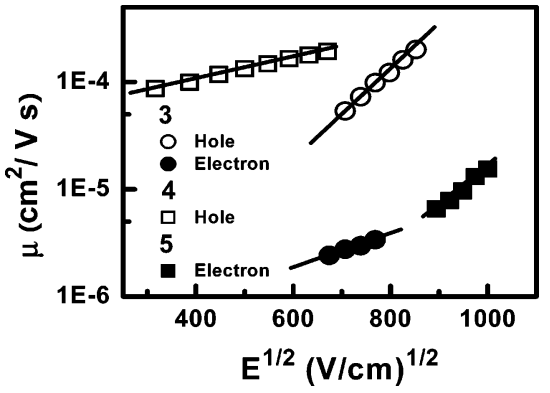

Figure 2. Mobilities of $\mathbf{3}-\mathbf{5}$ vs $E^{1 / 2}$ (the solid lines are fits to the Poole-Frenkel form).

root of the electric field; the straight lines follow the nearly universal Poole-Frenkel relationship, $\mu \propto \exp \left(\beta E^{1 / 2}\right)$, where $\beta$ is the Poole-Frenkel factor.

The observed hole $\left(\mu_{\mathrm{h}}=\mathrm{ca} .10^{-4} \mathrm{~cm}^{2} / \mathrm{Vs}\right)$ and electron $\left(\mu_{\mathrm{e}}=\right.$ ca. $\left.3 \times 10^{-6} \mathrm{~cm}^{2} / \mathrm{Vs}\right)$ mobilities of $\mathbf{3}$ are comparable to, but slightly lower than, those of its single-chromophore counterparts $\mathbf{4}$ and $\mathbf{5}$, respectively. The hybridization of the electron-donating character of the diphenylamino group with the electron-withdrawing character of the phenylbenzimidazole moiety leads to the novel bipolar $\mathbf{3}$ system exhibiting ambipolar carrier-transport character. The mobilities are compensated to a certain degree, however, by the spiro configuration of the two D-A chromophore branches hindering efficient intermolecular $\pi$-orbital interactions, which is consistent with the observed lower mobilities of $\mathbf{3}$ and $\mathbf{4}$ as compared to those of tetraphenylbenzidine (TAD) $)^{12}$ and TBPI, ${ }^{8}$ respectively (Figure S-4, Supporting Information).

To examine the potential application of $\mathbf{3}$ as an emitter in OLEDs, we designed three devices having the configuration ITO/PEDOT-PSS $(30 \mathrm{~nm}) / \mathbf{I}: 3(100 \mathrm{~nm})$; II: $\mathbf{3}(50 \mathrm{~nm}) / \mathbf{5}$ $(50 \mathrm{~nm})$; III: $\mathbf{4}(40 \mathrm{~nm}) / \mathbf{3}(30 \mathrm{~nm}) / \mathbf{5}(30 \mathrm{~nm}) / \mathrm{LiF}(0.5 \mathrm{~nm}) /$ $\mathrm{Al}(100 \mathrm{~nm})$. Table 2 summarizes the device characteristics.

The bipolar transport properties and suitable frontier orbital energies of $\mathbf{3}$ allowed us to realize a blue single-layer device. ${ }^{5}$

(11) (a) Borsenberger, P. M.; Weiss, D. S. Organic Photoreceptors for Imaging Systems; Marcel Dekker: New York, 1993. (b) Liao, Y.-L.; Lin, C.-Y.; Wong, K.-T.; Hung, W.-Y.; Chen, W.-J. Chem. Commun. 2007, 1831.

(12) Sara, T. P. I.; Fuhrmann-Lieker, T.; Salbeck, J. Adv. Funct. Mater. 2006, 19, 966. 
Table 2. EL Properties of Devices I-III

\begin{tabular}{|c|c|c|c|c|c|c|}
\hline device & $\begin{array}{c}\text { turn-on } \\
\text { voltage }(\mathrm{V})\end{array}$ & $\begin{array}{c}L_{\max } \\
\left(\mathrm{cd} / \mathrm{m}^{2}\right)\end{array}$ & $\begin{array}{c}I_{\max } \\
\left(\mathrm{mA} / \mathrm{cm}^{2}\right)\end{array}$ & $\begin{array}{l}\eta_{\text {ext } \max } \\
(\%, \mathrm{~cd} / \mathrm{A})\end{array}$ & $\begin{array}{l}\eta_{\mathrm{p}} \max \\
(\mathrm{lm} / \mathrm{W})\end{array}$ & $\begin{array}{l}\mathrm{CIE} \\
(x, y)\end{array}$ \\
\hline I & 4 & $\begin{array}{l}2800 \\
(19 \mathrm{~V})\end{array}$ & 830 & $0.52 \%, 0.61$ & 0.14 & $\begin{array}{r}0.15, \\
0 .\end{array}$ \\
\hline II & 3 & $\begin{array}{l}10600 \\
(17 \mathrm{~V})\end{array}$ & 2500 & $1.50 \%, 1.68$ & 1.10 & $\begin{array}{r}0.16, \\
0 .\end{array}$ \\
\hline III & 2.5 & $\begin{array}{l}21200 \\
(13.5 \mathrm{~V})\end{array}$ & 3500 & $1.57 \%, 1.90$ & 1.55 & $\begin{array}{r}0.16, \\
0.1\end{array}$ \\
\hline
\end{tabular}

The EL spectrum of device I is identical to the thin-film PL emission spectrum of $\mathbf{3}$, with Commission International d'Eclairage (CIE) coordinates of 0.15 and 0.14 . This singlelayer device exhibits a turn-on potential of $4 \mathrm{~V}$ and a maximum brightness of $2800 \mathrm{~cd} / \mathrm{m}^{2}$ at $830 \mathrm{~mA} / \mathrm{cm}^{2}(19 \mathrm{~V})$ and maximum quantum and power efficiencies of up to $0.53 \%(0.61 \mathrm{~cd} / \mathrm{A})$ and $0.14 \mathrm{~lm} / \mathrm{W}$, respectively. Nevertheless, the single-layer device still suffered from imbalanced charge recombination and a possible quenching effect by the cathode, which is a problem encountered frequently in OLED devices. ${ }^{13}$ In an attempt to mitigate the cathode quenching effect and improve electron transport into the emitter, in device II we inserted $\mathbf{5}$ between the $\mathbf{3}$ layer and the cathode. Both the brightness and EL efficiency were enhanced substantially relative to those of the single-layer device I (Table 2). This result indicates a more balanced electronhole recombination, which agrees with our TOF observations; i.e., 5 had better electron-transporting capability than $\mathbf{3}$. Replacing 5 with TPBI, a widely used electron-transporting and hole-blocking layer, led to a lower device efficiency $(1.3 \%, 0.7 \mathrm{~lm} / \mathrm{W})$. To further confine the emissive excitons within the $\mathbf{3}$ layer, we introduced $\mathbf{4}$ as a hole-transport layer to give the double-heterojunction device III. Figure 3 indicates that the current densities under the same potential decreased in the order III $>$ II $>$ I, suggesting that the double-heterostructure device enhanced the carrier injection and transport properties. Device III exhibited a rather low turn-on voltage of $2.5 \mathrm{~V}$ for a blue OLED, with pure emission from 3. This device achieved a high external quantum efficiency $(1.57 \%, 1.9 \mathrm{~cd} / \mathrm{A})$, a power efficiency of $1.55 \mathrm{~lm} /$ $\mathrm{W}$, and a maximum brightness of ca. $2.1 \times 10^{4} \mathrm{~cd} / \mathrm{m}^{2}$ at $13.5 \mathrm{~V}$. Furthermore, the quantum efficiency remained fairly high at high current densities $\left(1.35 \%\right.$ at $100 \mathrm{~mA} / \mathrm{cm}^{2}$; Figure S-5, Supporting Information).

(13) (a) Kulkarni, A. P.; Kong, X.; Jenekhe, S. A. Adv. Funct. Mater 2006, 16, 1057. (b) Wu, C.-C.; Lin, Y.-T.; Wong, K.-T.; Chen, R.-T.; Chien, Y.-Y. Adv. Mater. 2004, 16, 61.

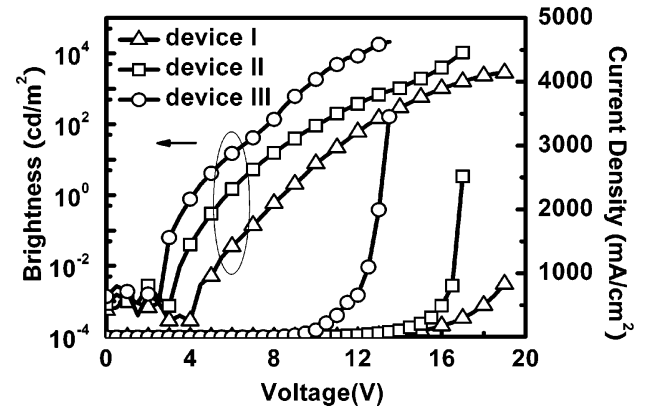

Figure 3. Plots of brightness and current density vs voltage for devices I-III.

In summary, we have synthesized and characterized an unprecedented blue-light emitting spiro-configured bipolar molecule (3), equipped with diphenylamino groups as electron donors and phenylbenzimidazole groups as electron acceptors. 3 exhibits a combination of the physical properties originating from its donor and acceptor groups. Its orthogonal molecular configuration is responsible for its high thermal and morphological stabilities. The bipolar character of $\mathbf{3}$ was evident from its reversible redox potentials, solvatochromic behavior in the excited state, and ambipolar carrier transport properties. These features allowed us to utilize $\mathbf{3}$ successfully in a single-layer device exhibiting blue-emission CIE coordinates of 0.15 and 0.14 , a turn-on potential of $4 \mathrm{~V}$, and a maximum brightness of $2800 \mathrm{~cd} / \mathrm{m}^{2}$ at $830 \mathrm{~mA} / \mathrm{cm}^{2}(19 \mathrm{~V})$. Employing a double heterostructure of $\mathbf{4 / 3 / 5}$ to confine the excitons in the emissive layer led to a blue OLED device displaying higher performance: brightness reaching as high as $21000 \mathrm{~cd} / \mathrm{m}^{2}$, efficiency of up to $1.9 \mathrm{~cd} / \mathrm{A}$, and a value of EQE of $1.57 \%$.

Acknowledgment. This work was financially supported by the National Science Council, Ministry of Education, and Ministry of Economic Affairs of Taiwan.

Supporting Information Available: Detailed experimental procedures, spectroscopic characterization of new compounds, cyclic voltammograms, solvent polarity dependent UV-vis and PL spectra, TOF photocurrent transients, and device characteristics. This material is available free of charge via the Internet at http://pubs.acs.org.

OL701994K 